\title{
Periodontal Disease Distribution, Risk Factors, and Importance of Primary Healthcare in the Clinical Parameters Improvement
}

\author{
Distribución de la Enfermedad Periodontal, Factores de Riesgo e Importancia \\ de la Atención Primaria en Salud en la Mejora de los Parámetros Clínicos
}

\author{
Norma Samanta Romero Castro1; Natividad Castro Alarcón²; Salvador Reyes Fernández'; \\ Eugenia Flores Alfaro'; Victor Othón Serna Radilla' \& Isela Parra Rojas ${ }^{2}$
}

\begin{abstract}
ROMERO, C. N. S.; CASTRO, A. N.; REYES, F. S.; FLORES, A. E.; SERNA, R. V. O. \& PARRA, R. I. Periodontal disease distribution, risk factors, and importance of primary healthcare in the clinical parameters improvement. Int. J. Odontostomat., 14(2):183-190, 2020.

ABSTRACT: The objective of this study is to show the distribution of periodontal disease, risk factors, and importance of primary healthcare, for the improvement of clinical parameters. Two phases study transversal and nonrandomized trial (before - after), with educational intervention and conservative treatment, were carried out at Dental School of the Universidad Autónoma de Guerrero México, in 161 subjects who met the inclusion criteria. Oral healthcare education was carried out as well as conservative periodontal treatment, with six months follow up. Clinical measurements were performed with a Williams probe, O'Leary plaque index, calculus index and dental mobility Miller method. Periodontal disease was found on $82 \%$ of all participants. Multinomial logistic regression analysis showed an odds ratio of $14.3(95 \% \mathrm{Cl}: 2.5,82.1), 13.4(95 \% \mathrm{Cl}: 1.7$, 103.5), 29.2 (95\% Cl: 3.2, 260.9) and 68 (95\% Cl: 6.6, 711.0) plaque in gingivitis, mild, moderate and severe chronic periodontitis, respectively. The longitudinal panel data analysis showed a significant effect $(p<0.001)$ in the mean decrease of the clinical parameters after intervention, probing depth $0.4 \mathrm{~mm} \mathrm{(95 \%} \mathrm{Cl:}-0.5,-0.3)$, pockets depth $1.1 \mathrm{~mm}(95 \% \mathrm{Cl}:-1.3,-0.9)$, amount of pockets $4.5(95 \% \mathrm{Cl}:-5.2,-3.7)$, bleeding $5.2(95 \% \mathrm{Cl}:-5.9,-4.5)$ and dental mobility 0.6 degrees $(95 \% \mathrm{Cl}:-0.7,-0.5)$. Primary healthcare is still the best option to improve the periodontal health in population who do not have access to specialty services. Dentists can achieve significant clinical improvement at very low cost, if they are aware of primary health care.
\end{abstract}

KEY WORDS: periodontal diseases, health education, conservative periodontal treatment, primary oral health care.

\section{INTRODUCTION}

Periodontal disease is considered a public health issue due to its high prevalence at a worldwide level, which oscillates between 35 and $51 \%$, even higher depending on the factors of study population (Aimetti et al., 2015). Currently there is inequity at a worldwide level regarding oral healthcare access; therefore marginalized groups have a larger prevalence of oral diseases (Gibson et al., 2016).

Periodontal dysbiotic inflammation has an adverse impact on systemic health, which begins to concern the medical community on developing countries. Diverse studies on oral microbial communities indicate that inflammatory pathology both at local and distant sites, may play an important role in the beginning and progression of some systemic diseases such as cardiovascular and respiratory diseases, premature births and underweight infants at birth, rheumatoid arthritis, diabetes mellitus, among others (Manjunath et al., 2011).

On private practice, the efforts in treatment of periodontal diseases have been steered towards surgery, after the conservative stage, with different

${ }^{1}$ Escuela Superior de Odontología de la Universidad Autónoma de Guerrero, México. Avenida Ruíz Cortínes S/N, Colonia Infonavit Alta Progreso Acapulco Guerrero, México.

${ }^{2}$ Doctorado en Ciencias Biomédicas de la Universidad Autónoma de Guerrero, México. Av. Lázaro Cárdenas S/N, Ciudad Universitaria Chilpancingo Guerrero, México.

${ }^{3}$ Laboratorio de investigación en Epidemiología Clínica y Molecular, Facultad de Ciencias Químico Biológicas, Universidad Autónoma de Guerrero, México. Av. Lázaro Cárdenas S/N, Ciudad Universitaria Chilpancingo Guerrero, México. 
types of grafts, oriented towards gaining a few millimeters of insertion; however, these procedures are neither indicated on all patients, nor on all sites. In general, they are carried out for intrabony defects (Jain et al., 2016).

Most of the population does not have access to this type of costly and privatized treatments, due to economic, geographic and ethnic reasons, being the oral cavity a site of social inequality since those who require the most dental care are those who are least likely to receive this type of care (Jamieson, 2016).

Non-surgical periodontal treatment which includes healthcare education, instructions on proper brushing technique and the use of hygiene accessories, scaling and root planning have shown to provide good results in patients and improvement in their dental hygiene (Woelber et al., 2016). With only conservative periodontal treatment, there has been an improvement in patients' periodontal conditions, as well as a decrease in pocket depth and gain in clinical insertion (Türkoglu et al., 2016). It is well known that the best prevention of odontogenic infections is correct oral hygiene (Robles Raya et al., 2017).

The state of Guerrero in the south of Mexico has extremely impoverished communities, indigenous ethnic groups and major sociocultural underdevelopment (Favila Tello \& Navarro Chávez, 2017), resulting in the apparition of favorable conditions for the development of periodontal disease, with a higher distribution compared to other populations, representing a major public health issue. The public healthcare system in Mexico does not have periodontics specialists and there are very few at a private level within the region. In the Dental School in the state of Guerrero, using the few available resources, the primary healthcare with conservative treatments are carried out, as well as oral health care promotion with motivational techniques, with the purpose of improving the oral condition of these population groups.

For the aforementioned reasons, our main objectives for this paper were to determine de distribution of periodontal disease within the study population and analyze its risk factors. We also evaluated the effect of primary healthcare an educational intervention together with a conservative treatment in the improvement of periodontal clinical parameters.

\section{MATERIAL AND METHOD}

The study was carried out among adults from 18 to 75 years old, men and women, who reside in the state of Guerrero, Mexico; from different state communities, who went to the external dental clinical service of the Dental School of the Guerrero Autonomous University (UAGro) in search of treatment, during the period comprising August 2015 to February 2016. The UAGro Ethics Committee approved the research protocol (authorization CB005/2015), which complied with the principles of the Helsinki Declaration, from the World Medical Association. Participants were informed about the procedures to be followed, and they signed a consent form. Pregnant or lactating women were excluded from the study, as well as patients with systemic diseases. People who did not conclude periodontal or laboratory studies, who had survey data missing or who did not return for the reassessment, were excluded from the study.

Diagnostic tests. The staff affiliated with the research was trained in terms of filling out the medical history, filling out the survey of variables not included on the medical history, oral examination with a mirror, periodontal probing, plaque and calculus index, oral healthcare education and motivational techniques, root scaling and planning. All patients had a glucose test carried out at the UAGro University Medical Service laboratory.

To evaluate the periodontal condition, probing was carried out by only one calibrated operator, with a Goldman-Fox/Williams probe. Clinical parameters in millimeters such as probing depth (PD), clinical attachment level (CAL), bleeding on probing (BOP) and dental mobility using the Miller method, were taken into consideration (O'Leary, 1974), and mobility degrees were added and divided between the number of teeth with mobility as to obtain the mobility average per patient. The O'Leary plaque index (O'Leary et al., 1972) was also determined as well as the calculus index in percentage, the same way as the plaque index was determined. Radiographic bone loss was determined by bite-wing and periapical x-rays.

Patients were considered as healthy when they did not have bleeding on probing, without color changes in the gingivae and did not present evidence of radiographic bone loss. Patients were diagnosed with gingivitis, when presented bleeding on probing, 
color changes in the gingivae, and no evidence of radiographic bone loss. Patients were considered as having periodontitis when they presented radiographic bone loss, $\mathrm{PD}>3 \mathrm{~mm}$, clinical attachment loss level (CAL), and dental mobility. These patients were grouped using the criteria of the International Classification for periodontal disease from the workshop in 1999 (American Academy of Periodontology, 2015) regarding mild chronic periodontitis with CAL of 1 to $2 \mathrm{~mm}$, moderate of 3 to $4 \mathrm{~mm}$ and severe of $\geq 5 \mathrm{~mm}$. Those who presented aggressive periodontitis were eliminated of the study but they did receive the intervention. Finally, 161 participants were included which were divided in 5 groups in accordance with their periodontal characteristics: healthy, with gingivitis, with mild, moderate and severe chronic periodontitis.

Educational intervention and conservative treatment. Once the diagnostic tests were carried out, all participants were instructed by means of flipcharts regarding brushing technique, use of dental floss and when were interdental brush and floss threaders necessary. Besides from using flipcharts to teach patients hygiene techniques a typodont teeth was used, as well and talks were held regarding oral healthcare education using images with consequences of bad dental and periodontal hygiene.

All participants were provided with the necessary accessories for proper oral hygiene. This educational intervention was reinforced in participants during three sessions, one per week. Patients with gingivitis had subgingival plaque elimination and scaling whenever necessary. Those who had periodontitis had conservative periodontal treatment, and those considered as periodontally healthy were referred to other clinics of the same dental school, so they could receive treatment for cavities or other disorders.

Scaling and root planning were carried out with universal periodontal curettes and with ultrasonic scalers, clinical parameters (PD, BOP and dental mobility) were measured once again six months after having carried out the conservative periodontal treatment and the educational intervention.

Statistical analysis. Patients were stratified in two groups: healthy and with periodontal disease (gingivitis and periodontitis). Qualitative variables were summarized in frequencies and quantitative variables without normality were summarized in medians and
25-75 percentiles. Median differences among groups (with or without periodontal disease) were analyzed with the Mann Whitney test, while frequencies were compared with chi-square (X2) test. Associations among different disease degrees with explanatory variables were evaluated using multinomial logistic regression models. Two models were applies, one for plaque and another one for calculus, they were not included together since they were considered as collinear. Finally, differences in measurements of initial clinical parameters and at 6 months were reported with the Wilcoxon statistic test for paired data. A longitudinal panel data analysis was carried out and reported a mean reduction of clinical parameters with the beta regression coefficient (b). The statistical analysis was carried out using the software STATA V.13, $p \leq 0.05$ value was considered statistically significant.

\section{RESULTS}

After the evaluation of 161 patients who complied with the inclusion criteria, $29(18.0 \%)$ were healthy, 34 had gingivitis (21.1\%), 21 had mild chronic periodontitis (13.0\%), 32 had moderate chronic periodontitis $(19.9 \%)$ and 45 with severe chronic periodontitis $(28.8 \%)$. Some of the factors that did not present significant differences between those who had the disease and those who were healthy were: belonging to an indigenous group, living on a rural or urban area, smoking, stress, mouth breathing, crowding and open bite. Table I shows socio demographic characteristics, systemic factors and oral characteristics of the study population, comparing the presence or absence of periodontal disease. It is noted that age, education, glucose levels, plaque and calculus indexes, retained root and Overhanging dental restorations presented significant differences.

Variables that remained significant in the multinomial logistic regression model were calculus and plaque, since they are considered as collinear, since one is the consequence of the other, two models are reported separately. Plaque was categorized with a cut-off point of up to $10 \%$, for such with few to no plaque at all and $11 \%$ and over for those who presented higher levels.

Patients who had an increase in the plaque level, had 14.4 times at higher risk of having gingivitis compared to healthy patients; 68.5 times at higher 
Table I. Sociodemographic, systemic and clinical-oral characteristics of the studied groups

\begin{tabular}{|c|c|c|c|c|}
\hline Characteristics & $\begin{array}{l}\text { Total } \\
n=161(100 \%)\end{array}$ & $\begin{array}{l}\text { With PD } \\
n=132(82 \%)\end{array}$ & $\begin{array}{l}\text { Without PD } \\
n=29(18 \%)\end{array}$ & $p$ value \\
\hline Age, years & $37(22-48)$ & $43(25.5-51)$ & $22(21-24)$ & $<0.001^{a}$ \\
\hline \multicolumn{5}{|l|}{ Gender, n (\%) } \\
\hline Female & $91(56)$ & $71(54)$ & $20(69)$ & \multirow{3}{*}{$0.135^{\mathrm{b}}$} \\
\hline Male & $70(44)$ & $61(46)$ & $9(31)$ & \\
\hline Total & $161(100)$ & $132(100)$ & $29(100)$ & \\
\hline \multicolumn{5}{|l|}{ Education, n (\%) } \\
\hline College & $66(41)$ & $41(31)$ & $25(86)$ & \multirow{4}{*}{$<0.001$} \\
\hline High School & 37 (23) & $36(27)$ & $1(4)$ & \\
\hline Junior High School & $20(12)$ & $17(13)$ & $3(10)$ & \\
\hline Primary school & $28(17)$ & $28(21)$ & 0 & \\
\hline Without education & $10(6)$ & $10(8)$ & 0 & \\
\hline Total & $161(100)$ & $132(100)$ & $29(100)$ & \\
\hline Glucose (mg/dl) & $75(75-90.5)$ & $75(75-93)$ & $75(75-77)$ & $0.018^{a}$ \\
\hline Plaque index & $49(24.1-7)$ & $57(34.4-80.7)$ & $5(3-7.5)$ & $<0.001 a$ \\
\hline Calculus index & $14.28(3-32.7)$ & $19.75(7.7-40)$ & $0(0-0)$ & $<0.001$ \\
\hline \multicolumn{5}{|l|}{ Retained root, n (\%) } \\
\hline Yes & $30(18.63)$ & $29(21.97)$ & $1(3.45)$ & \multirow{3}{*}{$0.020^{\mathrm{D}}$} \\
\hline No & $131(81.37)$ & $103(78.03)$ & $28(96.55)$ & \\
\hline Total & $161(100)$ & $132(100)$ & $29(100)$ & \\
\hline \multicolumn{5}{|c|}{ Overhanging restorations, $\mathrm{n}(\%)$} \\
\hline Yes & $22(14)$ & $12(9)$ & $10(34)$ & \multirow{3}{*}{$<0.001^{b}$} \\
\hline No & $139(86)$ & $120(91)$ & $19(66)$ & \\
\hline Total & $161(100)$ & $132(100)$ & $29(100)$ & \\
\hline
\end{tabular}

the risk of having severe periodontitis compared with healthy patients, adjusted by age and education. There is also an increase in the risk together with the increase of plaque, as the disease destruction stage progresses. When carrying out a continuous plaque analysis, it is observed that the OR are more reduced and interpreted differently. That is to say, the risk of having gingivitis increases 1.08 times per each plaque percent point increase compared to healthy patients, and the risk of having severe periodontitis increase 1.09 times per each plaque percent point increase compared to healthy patients (Table II).

Calculus were analyzed as continuous variable (calculus percentage), an increase per each calculus percent point increases 1.6 times the risk of having gingivitis compared to healthy people and 2.1 the risk of having severe periodontitis, also due to the increase of each calculus percent point, adjusted risks by age and education. A very subtle tendency is noted in the $\mathrm{OR}$ increase as the destruction stage of the disease progresses (Table II).
Table III shows the clinical improvement percentage, with the reduction in all periodontal clinical parameters after 6 months regarding health education and conservative periodontal treatment. The longitudinal panel data shows, that the intervention had an effect in the decrease in the mobility mean of 0.59 degrees; there was also a mean decrease in the rest of the clinical parameters: probing depth, pocket depth, number of pockets and number of teeth with bleeding on probing (Table IV).

\section{DISCUSSION}

The importance in the implementation of a health education program and of a periodontal conservative treatment for this population group is our main finding. It has been considered that periodontal disease is the most important public health issue, in particular in low income locations due to its high prevalence; and since an increase has been observed with the risk of having 
ROMERO, C. N. S.; CASTRO, A. N.; REYES, F. S.; FLORES, A. E.; SERNA, R. V. O. \& PARRA, R. I. Periodontal disease distribution, risk factors, and importance of primary healthcare in the clinical parameters improvement. Int. J. Odontostomat., 14(2):183-190, 2020.

Table II. Two models. Association between periodontal affection degree with plaque and calculus.

\begin{tabular}{|c|c|c|c|c|c|c|}
\hline Disease degrees & $\mathrm{OR}^{1}$ & $\mathrm{Cl} 95 \%$ & Valor $p$ & $\mathrm{OR}^{2}$ & $\mathrm{Cl} 95 \%$ & Valor $p$ \\
\hline \multicolumn{7}{|l|}{ Gingivitis } \\
\hline Plaque & 1.08 & $1.04, \quad 1.12$ & $<.001$ & 14.35 & $2.50,82.15$ & 0.003 \\
\hline Age & 1.04 & $.96,1.12$ & 0.264 & 1.05 & $.97, \quad 1.13$ & 0.197 \\
\hline Education & 1.68 & $.72, \quad 3.92$ & 0.227 & 1.72 & $0.78, \quad 3.82$ & 0.176 \\
\hline \multicolumn{7}{|l|}{ Mild periodontitis } \\
\hline Plaque & 1.05 & $1.01, \quad 1.10$ & 0.01 & 13.43 & $1.74,103.57$ & 0.013 \\
\hline Age & 1.08 & $1.01,1.17$ & 0.02 & 1.10 & $1.02,1.19$ & 0.014 \\
\hline Education & 1.84 & $.77, \quad 4.35$ & 0.16 & 1.80 & $.79, \quad 4.14$ & 0.161 \\
\hline \multicolumn{7}{|c|}{ Moderate periodontitis } \\
\hline Plaque & 1.07 & $1.02,1.11$ & $<0.001$ & 29.24 & $3.27,260.89$ & 0.002 \\
\hline Age & 1.14 & $1.05,1.22$ & $<0.001$ & 1.15 & $1.06,1.25$ & $<0.001$ \\
\hline Education & 2.25 & $.96,5.27$ & 0.060 & 2.29 & $1.01,5.19$ & 0.045 \\
\hline \multicolumn{7}{|c|}{ Severe periodontitis } \\
\hline Plaque & 1.09 & $1.04,1.13$ & $<0.001$ & 68.52 & $6.60,711.02$ & $<0.001$ \\
\hline Age & 1.19 & $1.10,1,28$ & $<0.001$ & 1.20 & $1.10,1.30$ & $<0.001$ \\
\hline Education & 2.17 & $.92,5.09$ & 0.074 & 2.31 & $1.01,5.23$ & 0.045 \\
\hline \multicolumn{7}{|l|}{ Gingivitis } \\
\hline Calculus & 1.62 & $1.20, \quad 2.19$ & 0.001 & & & \\
\hline Age & 1.01 & $0.93, \quad 1.10$ & 0.744 & & & \\
\hline Education & 1.62 & $0.57, \quad 4.61$ & 0.362 & & & \\
\hline \multicolumn{7}{|l|}{ Mild periodontitis } \\
\hline Calculus & 1.89 & $1.39, \quad 2.58$ & $<0.001$ & & & \\
\hline Age & 1.07 & $.97,1.18$ & 0.153 & & & \\
\hline Education & 1.35 & $.43,4.23$ & 0.598 & & & \\
\hline \multicolumn{7}{|c|}{ Moderate periodontitis } \\
\hline Calculus & 1.99 & $1.46, \quad 2.73$ & $<0.001$ & & & \\
\hline Age & 1.13 & $1.02, \quad 1.25$ & 0.012 & & & \\
\hline Education & 1.51 & $.48,4.76$ & 0.480 & & & \\
\hline \multicolumn{7}{|c|}{ Severe periodontitis } \\
\hline Calculus & 2.11 & $1.54, \quad 2.88$ & $<0.001$ & & & \\
\hline Age & 1.19 & $1.07, \quad 1.33$ & $<0.001$ & & & \\
\hline Education & 1.44 & $.44, \quad 4.69$ & 0.541 & & & \\
\hline
\end{tabular}

OR: Odds ratio obtained by multinomial logistic regression models

${ }^{1}$ Continuous variable

${ }^{2}$ Categorical variable

Table III. Changes on clinical parameters after educational intervention and conservative treatment.

\begin{tabular}{lllcc}
\hline \multicolumn{1}{c}{ Clinical parameter } & Before treatment & After treatment & $\begin{array}{c}\text { \% of clinical } \\
\text { improvement }\end{array}$ & $P$ value* $^{*}$ \\
\hline PD, mm & $1.9(1.6-2.2)$ & $1.5(1.3-1.8)$ & 20.8 & $<0.001$ \\
Pocket depth, mm & $4.6(4-5.6)$ & $3.6(3-4.1)$ & 21.1 & $<0.001$ \\
Amount of pockets & $7(3-18)$ & $3.5(1-11)$ & 50 & $<0.001$ \\
BOP (number of teeth) & $11.5(7-16)$ & $5(3-11)$ & 56.5 & $<0.001$ \\
Mobility degree & $1.2(0.5-1.8)$ & $0.5(0-1)$ & 57.3 & $<0.001$ \\
\hline
\end{tabular}

Data indicate median, 25 and 75 percentile

*Wilcoxon for paired data

Table IV. Longitudinal panel data analisis with educational intervention and conservative treatment, adjusted by age, sex and education.

\begin{tabular}{lcccc}
\hline Parámetro clínico & $\beta^{*}$ & Cl 95\% & $P$ value & $R^{2}$ \\
\hline PD, mm & -0.42 & $-0.52,-0.32$ & $<0.001$ & 0.38 \\
Pocket depth, mm & -1.09 & $-1.28,-0.90$ & $<0.001$ & 0.51 \\
Amount of pockets & -4.50 & $-5.24,-3.75$ & $<0.001$ & 0.54 \\
BOP (number of teeth) & -5.21 & $-5.95,-4.45$ & $<0.001$ & 0.61 \\
Mobility degree & -0.59 & $-0.66,-0.52$ & $<0.001$ & 0.70 \\
\hline
\end{tabular}

$\beta^{*}$ Regression coefficient obtained by lineal regression, adjusted by age, sex and education. 
certain systemic diseases such as atherosclerosis, acute myocardial infarction, and diabetes; among others, in patients with periodontitis (Shaw et al., 2016).

Our results show that periodontal disease is a public health issue with a high distribution, affecting populations on which socioeconomic conditions in general are unfavorable, with a distribution of $82 \%$ including gingivitis and periodontitis among study population. This study is concordant with reports showing a high prevalence, just for gingivitis it is between 50 and $94 \%$ (Li et al., 2010), or even larger such as $96.3 \%$, as reported by Bansal et al. (2015) in population from India.

Within risk-related factors, age obtained significant differences in the study and it is observed that the risk of having periodontal disease in more severe stages increases with age; such is concordant with what is already known in this regards and is confirmed on recent studies that show that at older age, higher the damage (Gil-Montoya et al., 2015). Though authors such as Lee et al. (2015) reported that after the age of 60 years old, periodontitis tends to decrease, this may be explained by anodontia which is common in older populations. Though diabetic patients were excluded from this study, higher glucose levels were observed on patients with periodontal disease compared with healthy patients. This result is in accordance with the study carried out by Choi et al. (2011) which noted that deeper pockets indicate a worse periodontal condition and is positively associated to higher levels of glucose, even in patients that are not diabetic yet.

Many of the local factors analyzed during the study did not show any association with periodontal disease, most likely due to the reduced sample size. Even with this situation, the presence of retained root and overhanging dental restorations show significant differences between healthy and sick patients; this is in accordance with what has been reported on literature, which mentions that anatomical characteristics of teeth and restorations affect the periodontium, and increase the risk of having the disease since bacterial accumulation is promoted (Blieden, 1999).

On the association analysis between risk factors with periodontal disease, it is shown that plaque and calculus are associated to the disease and a larger index of plaque and calculus increase the risk of having periodontal disease. It is well known that the main lo- cal factor is the plaque or biofilm and that its presence in retention sites worsens periodontal conditions (Mariotti \& Hefti, 2015). During a clinical study carried out by Shirmohamadi et al. (2016), the base analysis of the study population, reported significant differences in the plaque index of healthy and sick patients.

The periodontal treatment included root scaling and planing, focused in carrying out all the necessary maneuvers to eliminate local irritant factors and controlling systemic factors. On this stage of health education, it was necessary to teach brushing technique and the use of floss, the adequate way of using accessories such as floss threaders and interdental brushes, when necessary. Indications were customized for every patient since not all patients have the same diastema, or not all of them have fixed dental bridges. For such reason, all patients must receive indications in accordance with their particular characteristics, taking always into consideration age and capacity of executing these maneuvers. Health education is essential in the improvement of tissue conditions and to maintain the periodontium in good conditions after treatment. Multiple studies show that only hygiene instructions and non-surgical periodontal treatment favor improvement of tissues (Suvan, 2005). Authors such as Reisine et al. (2016) have recently shown that even on older adults living in impoverished conditions and who are handicapped, gingival and hygiene conditions can be improved, which results in a reduction of plaque after motivational oral health interventions.

During this study there was an improvement of periodontal tissues, with significant reduction in the number of pockets, probing depth and dental mobility, after the intervention. In accordance with this study, the first investigations carried out by Morrison et al. (1980) report that conservative periodontal treatment is enough to obtain an evident improvement on clinical parameters. Also, in accordance with the results of this study, Rhemrev et al. (2006) found a reduction in the probing depth after conservative periodontal treatment.

Dental mobility, probing depth and bleeding during probing in this study had a significant reduction after carrying out a longitudinal panel data lineal regression analysis, in accordance with what was recently reported by Jiao et al. (2017) where the effectiveness of periodontal conservative treatment was proven on a large population group in China, by reducing the same parameters. A lineal multilevel regression analysis showed that grade II and III mobility 
had significant reductions. Mean reduction in probing depth reported by them was $0.62 \mathrm{~mm}$, while on this study it was of $0.42 \mathrm{~mm}$.

One of the study constraints is that participants were self-selected when they arrived at the facilities of the Dental School to receive treatment, and most likely periodontal disease cases are over represented. However, taking into consideration there were patients who required diverse treatments such as cavity filling, third molar surgery, temporomandibular joint dysfunction or other conditions that have nothing to do with periodontitis, it was also possible to have periodontally healthy population. Another constraint was that marginalized groups of the city of Acapulco where the most represented in the sample in comparison with other remote communities from the state of Guerrero, due to the proximity to the facilities. Even with these constraints, there was representation from diverse communities since it is the only public school in the state where specialized attention is provided for the general population, at a minimal cost and even at no cost, such as in the case of these studies, since county health services of the communities only look after general health problems and they are non-existent, or not available in all regions.

We do not know within this study which improvement percentage is due to educational intervention and which percentage is due to manual instrumentation. What is certain is that both are still a fundamental and inseparable part of the conservative stage of periodontal treatment.

\section{CONCLUSION}

Our results show that periodontal disease distribution is higher on marginalized groups, that the main associated factors are local irritants which have been widely reported, mainly plaque. Health education and conservative mechanical maneuvers are effective in improving periodontal clinical parameters.

Though this information is widely known, it may be useful for dissemination among the medical community and healthcare staff, for promotion and dissemination of oral health education and conservative periodontal treatment, to which a large sector of the society has access. Both can be carried out on remote sites, with little infrastructure, by means of dental brigades, they can even be carried out by well-trained dental students. Systemic complications may be avoidable in the future.

Ethical approval. The Institutional Ethics Committee approved the research protocol (authorization CB-005/ 2015), which complied with the principles of the Helsinki. Declaration, from the World Medical Association. Informed consent was obtained from all individual participants included in the study.

\section{ACKNOWLEDGEMENTS}

We thank the students of the fifth and sixth semesters, of the generation 2013-2108 of the Superior School of Dentistry of the UAGro; for their participation in the recruitment of patients.

Este estudio se realizó dentro de las instalaciones de la Escuela Superior de Odontología de UAGro, que cuenta con equipos del Programa de Fortalecimiento Institucional Integral (PIFI), que forma parte de las políticas públicas del gobierno mexicano, hacia la educación superior en el país.

ROMERO, C. N. S.; CASTRO, A. N.; REYES, F. S.; FLORES, A. E.; SERNA, R. V. O. \& PARRA, R. I. Distribución de la enfermedad periodontal, factores de riesgo e importancia de la atención primaria en salud en la mejora de los parámetros clínicos. Int. J. Odontostomat., 14(2):183-190, 2020.

RESUMEN: El objetivo del estudio fue mostrar la distribución de la enfermedad periodontal, los factores de riesgo y la importancia de la atención primaria de salud, para la mejora de los parámetros clínicos. Material y método: Estudio de dos fases transversal y no aleatorizado (antes - después), con intervención educativa y tratamiento conservador, realizado en la Facultad de Odontología de la Universidad Autónoma de Guerrero México, en 161 sujetos que cumplieron con los criterios de inclusión. Se llevó a cabo una educación sanitaria oral, así como un tratamiento periodontal conservador, con un seguimiento de seis meses. Las mediciones clínicas se realizaron con una sonda Williams, el índice de placa O'Leary, el índice de cálculo y el método Miller de movilidad dental. Resultados: se encontró enfermedad periodontal en el $82 \%$ de todos los participantes. El análisis de regresión logística multinomial mostró un odds ratio de 14.3 (IC 95 \%: 2.5, 82.1), 13.4 (IC 95 \%: 1.7, 103.5), 29.2 (IC $95 \%: 3.2,260.9$ ) y 68 (IC $95 \%: 6.6,711.0)$ placa en gingivitis, periodontitis crónica leve, moderada y grave, respectivamente. El análisis de datos del panel longitudinal mostró un efecto significativo $(p<0.001)$ en la disminución media de los parámetros clínicos después de la intervención, profundidad 
de sondeo $0.4 \mathrm{~mm}$ (IC $95 \%$ : -0.5, -0.3), profundidad de bolsiIlos $1.1 \mathrm{~mm}$ (IC $95 \%:-1.3,-0.9)$, cantidad de bolsillos 4.5 (IC $95 \%$ : -5.2, -3.7), hemorragia 5.2 (IC $95 \%$ : -5.9, -4.5) y movilidad dental 0.6 grados (IC $95 \%$ : - $0.7,-0.5)$. Conclusiones: la atención primaria de salud sigue siendo la mejor opción para mejorar la salud periodontal en la población que no tiene acceso a servicios especializados. Relevancia clínica: Ios dentistas pueden lograr una mejora clínica significativa a un costo muy bajo, si conocen la atención primaria de salud.

PALABRAS CLAVE: enfermedad periodontal, educación para la salud, tratamiento periodontal conservador, atención primaria en salud oral.

\section{REFERENCES}

Aimetti, M.; Perotto, S.; Castiglione, A.; Mariani, G. M.; Ferrarotti, F. \& Romano, F. Prevalence of periodontitis in an adult population from an urban area in North Italy: findings from a cross-sectional populationbased epidemiological survey. J. Clin. Periodontol., 42(7):622-31, 2015.

American Academy of Periodontology Task Force Report on the Update to the 1999 Classification of Periodontal Diseases and Conditions. J. Periodontol., 86(7):835-8, 2015.

Bansal, M.; Mittal, N. \& Singh, T. B. Assessment of the prevalence of periodontal diseases and treatment needs: A hospital-based study. J. Indian Soc. Periodontol., 19(2):211-5, 2015

Blieden, T. M. Tooth-related issues. Ann. Periodontol., 4(1):91-7, 1999.

Choi, Y. H.; McKeown, R. E.; Mayer-Davis, E. J.; Liese, A. D.; Song, K. B. \& Merchant, A. T. Association between periodontitis and impaired fasting glucose and diabetes. Diabetes Care, 34(2):381-6, 2011.

Favila Tello, A. \& Navarro Chávez, J. C. L. Desigualdad educativa y su relación con la distribución del ingreso en los estados mexicanos. CPU-e Rev. Investig. Educ., (24):75-98, 2017.

Gibson, L. B.; Blake, M. \& Baker, S. Inequalities in oral health: the role of sociology. Community Dent. Health, 33(2):156-60, 2016.

Gil-Montoya, J. A.; Ferreira de Mello, A. L.; Barrios, R.; Gonzalez Moles, M. A. \& Bravo, M. Oral health in the elderly patient and its impact on general well-being: a nonsystematic review. Clin. Interv. Aging, 10:4617, 2015.

Jain, D.; Sawhney, A.; Gupta, B.; Sharma, S.; Juneja, S.; Juneja, M.; Sharma, S. \& Patil, N. Clinical and radiologic evaluation of regenerative potential of NHA paste and DBM in the treatment of periodontal intra-bony defects -A randomized control trial. J. Clin. Diagn. Res., 10(9):ZC74-ZC79, 2016.

Jamieson, L. M. The mouth as a site of structural inequalities; an introduction. Community Dent. Health, 33(2):151, 2016.

Jiao, J.; Shi, D.; Cao, Z. Q.; Meng, H. X.; Lu, R. F.; Zhang, L.; Song, Y. \& Zhao, J. R. ffectiveness of non-surgical periodontal therapy in a large Chinese population with chronic periodontitis. J. Clin. Periodontol., 44(1):42-50, 2017.

Lee, J. H.; Lee, J. S.; Park, J. Y.; Choi, J. K.; Kim, D. W.; Kim, Y. T. \& Choi, S. H. Association of lifestyle-related comorbidities with periodontitis: a nationwide cohort study in Korea. Medicine (Baltimore), 94(37):e1567, 2015.

Li, Y.; Lee, S.; Hujoel, P.; Su, M.; Zhang, W.; Kim, J.; Zhang, Y. P. \& DeVizio, W. Prevalence and severity of gingivitis in American adults. Am. J. Dent., 23(1):9-13, 2010.

Manjunath, B. C.; Praveen, K.; Chandrashekar, B. R.; Vatchala Rani, R. M. \& Bhalla, A. Periodontal infections: a risk factor for various systemic diseases. Natl. Med. J. India, 24(4):214-9, 2011.

Mariotti, A. \& Hefti, A. F. Defining periodontal health. BMC Oral Health, 15 Suppl. 1:S6, 2015.
Morrison, E. C.; Ramfjord, S. P. \& Hill, R. W. Short-term effects of initial, nonsurgical periodontal treatment (hygienic phase). J. Clin. Periodontol., 7(3):199-211, 1980.

O'Leary, T. Indices for measurement of tooth mobility in clinical studies. J. Periodontal Res. Suppl., 14:94-105, 1974.

O'Leary, T. J.; Drake, R. B. \& Naylor, J. E. The plaque control record. J. Periodontol., 43(1):38, 1972

Reisine, S.; Schensul, J. J.; Goldblatt, R.; Radda, K.; Foster-Bey, C.; AcostaGlynn, C.; Miron-Carcamo, L. \& loannidou, E. A bi-level intervention to improve oral hygiene of older and disabled adults in low-income housing: results of a pilot study. Community Dent. Health, 33(2):12732, 2016.

Rhemrev, G. E.; Timmerman, M. F.; Veldkamp, I.; Van Winkelhoff, A. J. \& Van der Velden, U. Immediate effect of instrumentation on the subgingival microflora in deep inflamed pockets under strict plaque control. J. Clin. Periodontol., 33(1):42-8, 2006.

Robles Raya, P.; Javierre Miranda, A. P.; Moreno Millán, N.; Mas Casals, A.; de Frutos Echániz, E. \& Morató Agustí, M. L. Manejo de las infecciones odontogénicas en las consultas de atención primaria: ¿antibiótico?. Aten. Prim., 49(10):611-8, 2017.

Shaw, L.; Harjunmaa, U.; Doyle, R.; Mulewa, S.; Charlie, D.; Maleta, K.; Callard, R.; Walker, A. S.; Balloux, F.; Ashorn, P.; et al. Distinguishing the signals of gingivitis and periodontitis in supragingival plaque: a cross-sectional cohort study in Malawi. Appl. Environ. Microbiol., 82(19):6057-67, 2016.

Shirmohamadi, A.; Chitsazi, M. T.; Faramarzi, M.; Salari, A.; Alavi, F. N. \& Pashazadeh, N Effect of non-surgical periodontal treatment on transferrin serum levels in patients with chronic periodontitis. J. Dent. Res. Dent. Clin. Dent. Prospects, 10(3):169-75, 2016.

Suvan, J. E. Effectiveness of mechanical nonsurgical pocket therapy. Periodontol. 2000, 37:48-71, 2005.

Türkog lu, O.; Eren, G.; Emingil, G.; Azarsız, E.; Kutukculer, N. \& Atilla, G. Does smoking affect gingival crevicular fluid LL-37 levels following nonsurgical periodontal treatment in chronic periodontitis? Arch. Oral Biol., 61:98-105, 2016

Woelber, J. P.; Spann-Aloge, N.; Hanna, G.; Fabry, G.; Frick, K.; Brueck, R.; Jähne, A.; Vach, K. \& Ratka-Krüger, P. Training of dental professionals in motivational interviewing can heighten interdental cleaning self-efficacy in periodontal patients. Front. Psychol., 7:254, 2016.

Corresponding author:

Norma Samanta Romero Castro

Escuela Superior de Odontología

Universidad Autónoma de Guerrero

México. Avenida Ruíz Cortínes S/N

Colonia Infonavit Alta Progreso

Acapulco Guerrero

Cp 39610

MÉXICO

Email: samsalperio@gmail.com
Received: 21-10-2019

Accepted: 19-12-2019 